care, combined with the increasing overattending of emergency wards, indicated that the prehospital care structure was imperfect. Decision makers, who have in their charge to regulate the care system (Regional Union of the Social Security Offices [URCAM], Regional Hospitalization Agency [ARH]) used this study to establish an optimal organization for the use of emergency wards.

Key words: characteristics; emergency wards; patients; prehospital care; utilization

E-mail: ersm63.doc@wanadoo.fr

Prehosp Disast Med 2001;16(2):s29.

\section{Activities of JMTDR in Sumatra}

\section{Nobuo Fuke; ${ }^{1}$ Kenji Taki, ${ }^{2}$ Hiroyuki Yokota, ${ }^{3}$ \\ Naomi Nishida; Rumi Yoshioka; Tomoko Miyazaki; \\ Miwako Fukui; Saeko Yamamoto; Naomi Nonaka; \\ Mutsuo Ishizawa; Tsutomu Yamagishi; Hideaki Kuroha; Junko Okumura}

Japan Medical Team for Disaster Relief: 1. Teikyo University Ichihara Hospital; 2. Saga Medîcal School; 3. Tama-Nagayama Medical Center; Nipppon Medical School, Tokyo, JAPAN

Introduction: On 04 June 2000 at 23:28 hours, an earthquake of 7.4 magnitude on the Richter scale struck the southwest coast of Sumatra Island, Indonesia. The initial report said that more than 900 thousands people were involved, and that at least 58 persons lost their lives. Bengkulu City, the state capital of Bengkulu, and its surrounding area were affected. Entrance into the buildings of Yunus Hospital, the largest medical facility in the area and one of the class B hospitals of the nation, was prohibited for security reasons, and hence, all in-patients were accommodated in tents.

Methods: The Japanese Government dispatched its volunteer-based, medical team, JMTDR (Japan Medical Team for Disaster Relief), and the team arrived at the Bengkulu airport 81 hours after the eruption. The JMTDR established a field clinic in the front yard of Yunus Hospital in cooperation with the local headquarter. Information that many injured victims in a mountainous area could not come to see a doctor prompted us to start another field clinic in Tais, a suburb of Bengkulu. A Singapore army team came first and established a field clinic with minor surgery services in Yunus Hospital, and a Taiwanese team built its facility as well in Sukaraja village near Bengkulu. The JMDTR focused its activities on providing medical care for the most vulnerable, namely children and then, the elderly.

Results: The team saw a total of 526 patients (453 in Yunus, and 73 in Tais) within ten days. The frequency distribution of the medical problems seen in Yunus was: $28 \%$ respiratory diseases; $16 \%$ minor psychiatric disorders such as headache, sleeplessness, or fear sensation; $15 \%$ trauma; and $9 \%$ gastrointestinal diseases. On the other hand, we mainly saw trauma patients in Tais (88\%) and in Yunus (86\%). Eighty-two percent of them in Tais lived within 40 minutes distance on foot or by car, but some of the patients $(1.2 \%)$ took more than 90 minutes to come to our clinics.
The Indonesian Government declared that all medical services associated with the earthquake were free, but this announcement was unknown to most of the people. The JMTDR offered them free and accessible medical services in the acute phase.

Conclusion: The rapid establishment of a field clinic affords time to the local medical facilities to reorganize and restore their abilities in this kind of disastrous situation.

Key words: clinics; earthquake; field clinics; hospitals; infrastructure; Japan Medical Team for Disaster Relief (JMTDR); responses

Prehosp Disast Med 2001;16(2):s29.

\section{Ingestion of Major Caustic Substances by Children L. Gabilly; G. Bagou; N. Richard; O. Péguet; D.Floret; P. Petit \\ Lyon, FRANCE}

Introduction: The ingestion of caustic substances constitutes more than a third of domestic accidents in developed countries: $80 \%$ of them concern children under the age of 5 years. Clinical signs either are atypical and limited, or missing half of the time, and lead to an underestimate of the seriousness of the ingestion.

Methods: This retrospective study (1984 to 2000) on 14 children hospitalised for accidental ingestion of major caustic substances in the intensive care unit of EdouardHerriot Hospital in Lyon).

Results: The studies showed that these substances were various: $79 \%$ ingested bases; $14 \%$ acids, and $7 \%$ oxidisers (concentrated bleach). Most of the children were $<5$ years old ( $57 \%$ of them were between 1.5 and 3 years old). All of them showed, at sometime, discrete clinical signs: oral burns $(43 \%)$, oral oedema $(36 \%)$, hypersialorrhoea and vomiting (29\%), dysphagia and thoracic pains (22\%), and premature fevers $(14 \%)$. A systematic fiberoscopy indicated $100 \%$ of digestive lesions, $50 \%$ of them being gastric lesions. Ingested bases involved $67 \%$ of stage II mucous lesions (as for endoscopic classification): ulcerations, and intense oedema. They also involved $33 \%$ of stage III mucous lesions: ulcerations, oedema and profuse bleedings. Acids caused $50 \%$ of the stage II lesions and $50 \%$ of stage III lesions. The only case caused by an oxidiser involved a stage II lesion. Every patient was treated: $55 \%$ of dilations and surgical procedures for stage II lesions, and $80 \%$ of them for stage III lesions. Complications occurred frequently (60\%), either immediately (chemical epiglottitis) or occurring as long as one year later (lesional or iatrogenical affections). Anamnesia was difficult, practically speaking. Some procedures are dangerous: vomiting, drinks, neutralisations, and stomach tube insertion. The initial undertaking is symptomatic. The child is to be steered within a structure allowing the making of an oesophagogastric fiberoscopy, which always is necessary $50 \%$ of absence of correlation between causticity, ingested quantity, and clinical signs). A cervicothoracic $x$-ray must precede the fiberoscopy when a perforation is suspected. One-third showed the complications, $10 \%$ of which are related to stenosing aftereffects. The risk of later development of 
cancerisation is multiplied by 1,000 .

Therefore, any ingestion of major caustic substances by children is serious. The clinical signs are to be accurately searched for, and a premature complication must be avoided. An endoscopic investigation in a specialised unit is necessary. More binding commercial legislation (as for dilution, presentation, and distribution) would be useful.

Key words: caustics; children; complications; endoscope; ingestions; pathology

Prehosp Disast Med 2001;16(2):s30.

\section{Rescue Clearing in Lyon in the Twentieth Century L. Gabilly; G. Bagou; J.M. Sapori; M. Rebreyend-Colin; G. Prost; P. Petit Lyon, FRANCE}

Several dramatic landslides occurred in Lyon in the 20th century. Expert's reports were obtained on many of them. These catastrophes claimed 40 casualties in 1930, 30 casualties in 1932, and 3 in 1977. Other landslides occurred, but claimed no casualties.

The general interpretation of the accidents indicates that these landslides are not inevitable. The weak points are the nature of the ground, the age of the buildings, and the existence of 2,000-year-old subterranean galleries. Hence, more than 30 landslides occurred on Lyon hills in 1983, due to an exceptional amount of rainfall. As for prevention, some parameters - such as the maintenance of the walls and of the drainage network - can be mastered and the emptying of waters through cesspools also needs to be suppressed. On the other hand, since the catastrophe of 1930 , a Technical Committee (Commission des Balmes) has been created. Its role is to check the solidity of the buildings on the concerned hills, and to define risk areas (setting of ground instability levels of assumption, granting of construction licenses).

Firemen are trained for rescue clearing at different levels: from elementary training to upgraded levels. There are several rescue units - a team unit, a group unit, and a section unit-and their equipment includes-ropes, pulleys, beams, and listening devices for searching for buried people. The vehicles all are appropriate: light colored for recognition and of average weight for first aid equipment, and large ones for logistical support. For large-scale catastrophes, specialized units are available to firemen: rescue clearing mobile column (by rail or road), and specialized airlifted detachments (for helping other countries). These particular rescue means can have quite short intervention delays and are autonomous on-site. When several rescue detachments are acting in a same area, an operating coordination advanced detachment ('Détachement avancé de coordination opérationnelle'-DACO) coordinates the intervention of the various units and communicates with local authorities. A medical support detachment ('Détachement d'appui médical'or DAM) is required, and takes charge of an advanced medical post that ensures the triage and the treatment of the victims who, once stabilized, are evacuated. The rapid medical intervention civil security element ('Elément de sécurité civile rapide d'inter- vention médicale'-ESCRIM) is a surgical technical platform whose hospital staff aims at operating upon some of the victims coming from the DAM. Responding to the geological and geotechnical risks of Lyon hills and to experts' reports, the firemen's rescue operating seems to look appropriate, for local interventions as well as for external ones. Prevention, as a result of Lyon experiences, also seems effective: the number of catastrophes and their human effects have decreased.

Key words: casualty clearing; firefighters; interventions; landslides; logistics; preparedness; rescue; responses Prehosp Disast Med 2001;16(2):s30.

\section{Construction of a Medical Evacuation System in Case of Air Raid on Cities GAO-Jiren;Zhong-Guiling; LI-Ting}

Military Medical Service Department of the Second Military Medical College, Shanghai, CHINA

Introduction: A Medical Evacuation System refers to the organizing and operating a system for evacuating for the sick and wounded during wartime. When the number of the nonaffected is large, the rational deployment of the medical evacuation system, on one hand, determines whether medical treatment will be implemented fully; on the other hand, it plays an important role in speeding up medical rescue.

Hypothesis: In accordance with the features of contemporary, high-tech regional, war, air raid in cities, and taking such factors as city size, population density, and defense levels into account, the paper is devoted to the discussion on how to achieve a rational medical evacuation system. It proposes that in small cities a two-level medical rescue-rescue at the scene and treatment in medical organizations-is effective. In midsized or large cities, a three-level medical rescue -rescue at the scene, emergency treatment in medical stations and special treatment in hospitals-is effective. Moreover, the paper outlines the differences in the tasks of the respective levels of rescue.

In addition, in order to fulfill a rational deployment of medical organizations and to guarantee good quality of medical treatment, the following measures should be brought about:

1. Estimating nonaffected according to anti-air raid plan

2. Carrying out army-civilian joint rescue

3. Standardizing medical evacuation documents and checking accuracy of enrollment statistics of military medicine

4. Implementing military organization and equipment, performing stimulated training in order to reach a quick reaction

Key words: air raid; care levels; civilian; evacuation; military; records; rescue; war

Prehosp Disast Med 2001;16(2):30. 